\title{
ROLE OF SAWDUST IN THE REMOVAL OF IRON FROM AQUEOUS SOLUTION
}

\author{
H.B. Senin ${ }^{*}$, O. Subhi, R. Rosliza, N. Kancono, M.S. Azhar, \\ S. Hasiah, and W.B. Wan Nik \\ Faculty of Science and Technology, \\ College University of Science and Technology Malaysia KUSTEM), \\ 21030 Kuala Terengganu, Terengganu, Malaysia
}

Received 28 September 2005

\begin{abstract}
Sawdust, inexpensive material has been utilized as an absorbent for the removal of iron from aqueous solution for their safe disposal. The adsorption experiments of untreated sawdust (SD) and treated sawdust (SDC) have been carried out at room temperature using the batch test. The Langmuir and Freundlich isotherms were used to observe sorption phenomena of sawdust in the removal of iron. The results indicate that the sawdust was capable in removing iron in aqueous solution. The results have shown that the Langmuir isotherm was found well fitted into the experimental data as compared to the Freundlich isotherm. It was found that, chemisorptions and physisorption were the prime mechanism for the process of adsorption to occur between the sawdust and iron. The results also proved that the acid sulphuric treated sawdust is much better than that of untreated sawdust as an adsorbent for iron.
\end{abstract}

\section{INTRODUCTION}

In recent years considerable attention has been devoted to the study of removal of heavy metal ions from solution by adsorption using agricultural materials such as waste wool, nut wastes, tree barks, modified cotton and sawdust [1]. Many agricultural byproducts such as bark and sawdust are low cost (or no economic value) materials. Sawdust from timber industry is often considered as waste material and widely available. Iron impregnated sawdust has been used as an adsorbent for phenolic compounds. Some previous investigations on the removal of heavy metal ion with sawdust have been reported [2]. The present study undertakes the adsorption capacity of maple sawdust for the removal of iron from aqueous systems.

\section{MATERIALS AND METHODS}

The untreated and treated sawdust were used as an absorbent for the removal of iron from aqueous solutions. The sawdust was sieved in range of $850 \mu \mathrm{m}$ to standardize the size of the sample and washed several times with distilled water. Untreated sawdust was dried in sunlight and treated sawdust mixed with sulphuric asid $(1 \mathrm{M})$ was dried at $110^{\circ} \mathrm{C}$. The initial concentration $\mathrm{Fe}$ of $0,1.75,3.5,7.0$ and $14.0 \mathrm{mg} / \mathrm{L}$ were used. Typically, $0.5-1.0 \mathrm{~g}$ sawdust

${ }^{*}$ Corresponding author e-mail: senin@kustem.edu.my 
was added in separate flasks each containing $100 \mathrm{ml}$ of the test solution of Fe and stirred in a shaker at $200 \mathrm{rpm}$. After reaching target contact time, suspensions were filtered and analyzed using an atomic absorption spectrometer (AAS). The adsorption experiments were carried out at room temperature and five hours was judged to be sufficient to reach equilibrium.

\section{RESULTS AND DISCUSSION}

\subsection{Effect of concentrations}

Figure 1 illustrates the sorption of iron onto the sawdust for different initial concentrations of Fe. It can be seen that the adsorption of iron increased with increasing of concentrations of Fe solution.

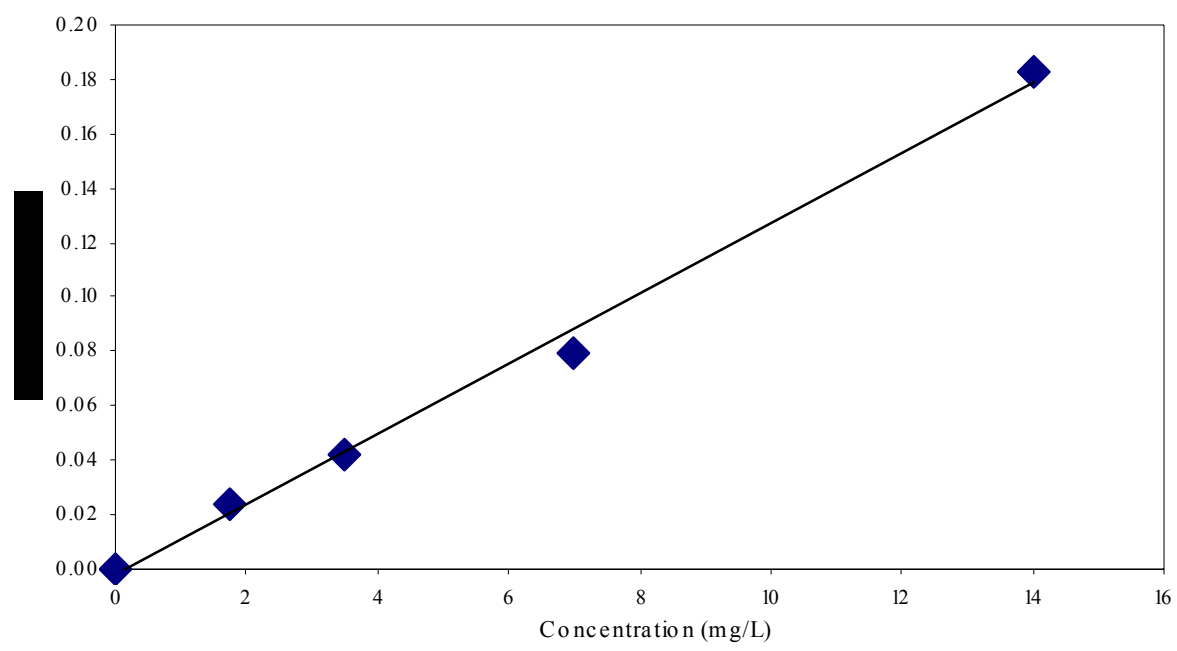

Fig. 1: $\quad$ Absorbance vs. concentration (calibration curve for Fe (II))

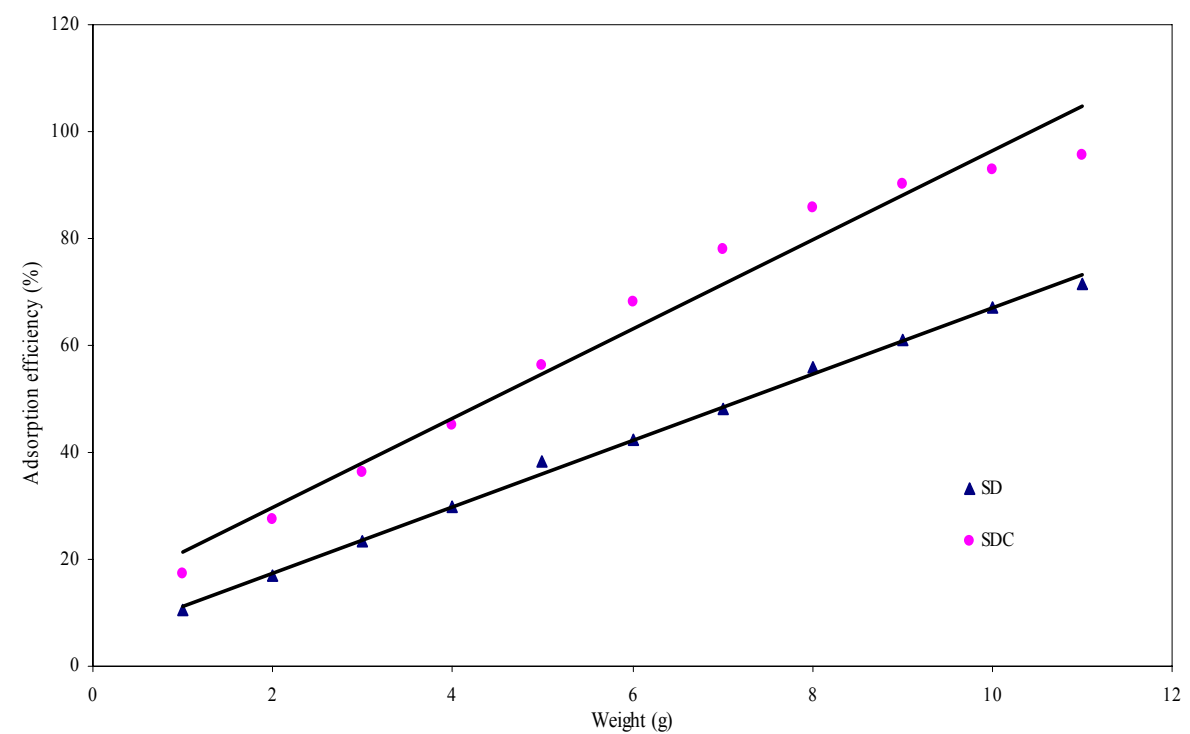

Fig. 2: $\quad$ Adsorption efficiency of Fe (II) using SD and SDC 


\subsection{Effect of adsorbent}

Figure 2 shows that the adsorption efficiency iron by using SD and SDC. The results had shown that the adsorption efficiency for iron by both SD and SDC increased with the addition of sawdust. The maximum adsorption by SD was found to be $71.7 \%$ whereby for the SDC was $95.7 \%$. As a consequence SDC has more affinity for adsorption of iron as compared to that of SD.

\subsection{Adsorption models and mechanism}

The simplest adsorption is based on the assumptions that every adsorption site is equivalent and that the ability of a particle to bind together is independent of whether or not adjacent sites are occupied [1]. The Langmuir and Freudlich isotherms described well for the observed sorption phenomenon of iron. Figures 3 and 4 display S-type shape for sorption isotherm for SD and SDC which describes the interaction of the adsorbate and the adsorbent. It showed that the relation of adsorbent dosage increases with the increments of equilibrium concentration obtained.

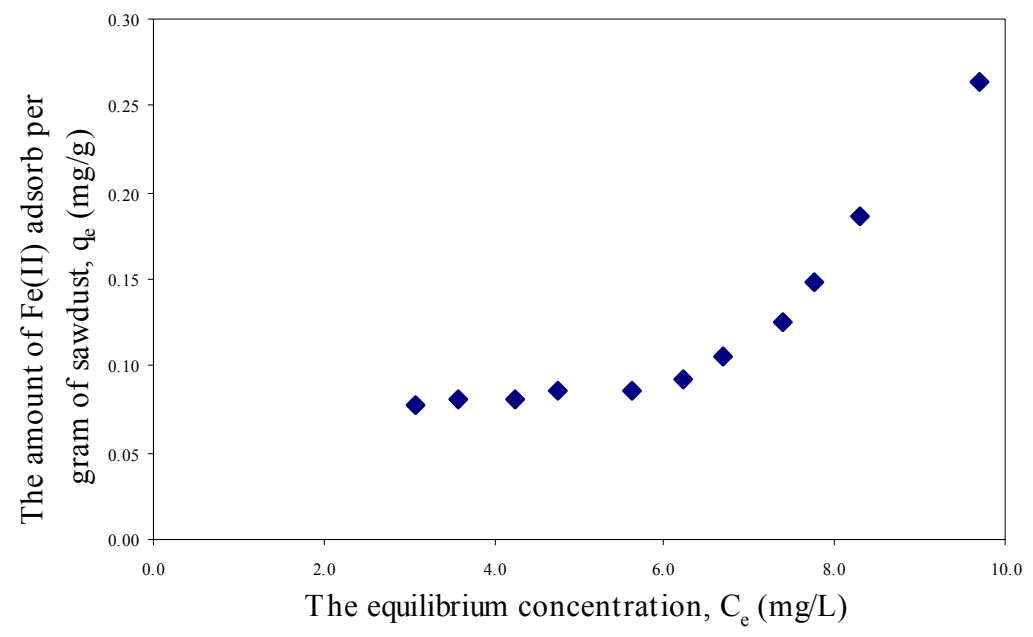

Fig. 3: $\quad q_{e}$ vs. $C_{e}$ (batch test) by using $S D$

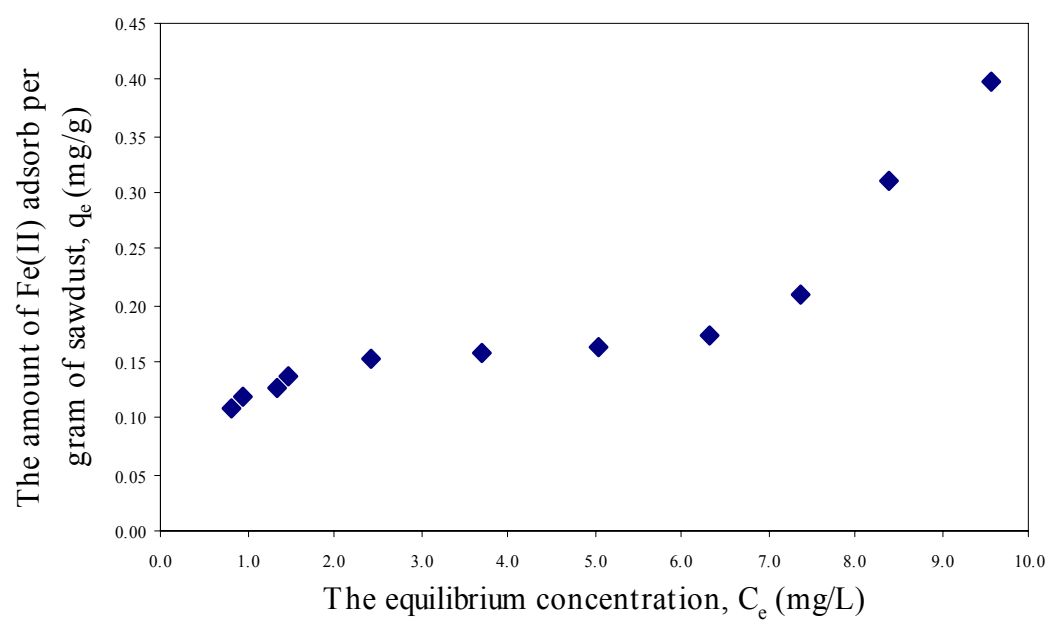

Fig. 4: $\quad q_{e}$ vs. $C_{e}$ (batch test) by using $S D C$ 
To analyze the fitness of adsorption isotherm to the experimental, the data for the uptake of metal ions by sawdust has been determined in accordance with a linear form of Langmuir isotherm equation [3]:

$$
\frac{1}{q_{e}}=\frac{1}{a b \cdot C_{e}}+\frac{1}{a}
$$

The slope of the graph represented by $1 / a b$ while $1 / a$ is shows the interception of the graph on the Y-axis. The constant $a$ refers to the adsorption capacity and constant $b$ is an indicator for molecular size of absorbate. The linear line of Langmuir equation fitted well into the experimental data as shown in Figs. 5 and 6.

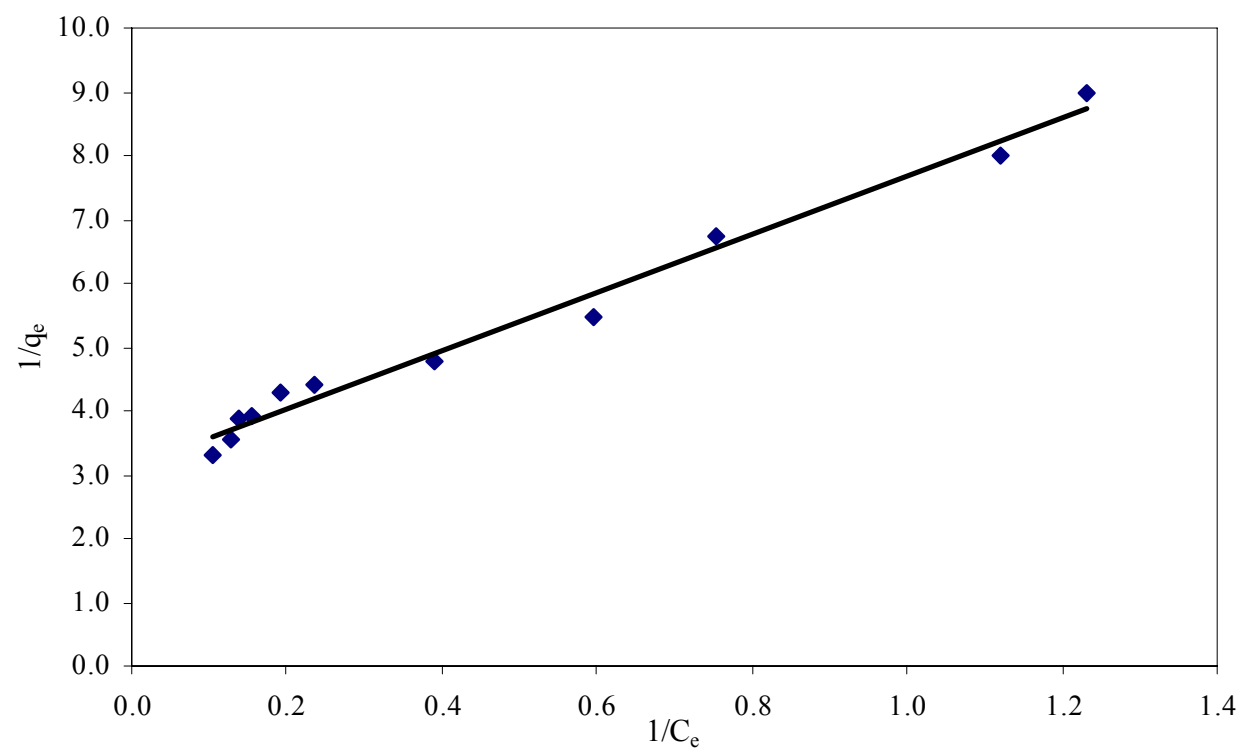

Fig. 5: $\quad$ Linear Langmuir isotherm of Fe (II) sorption on SD

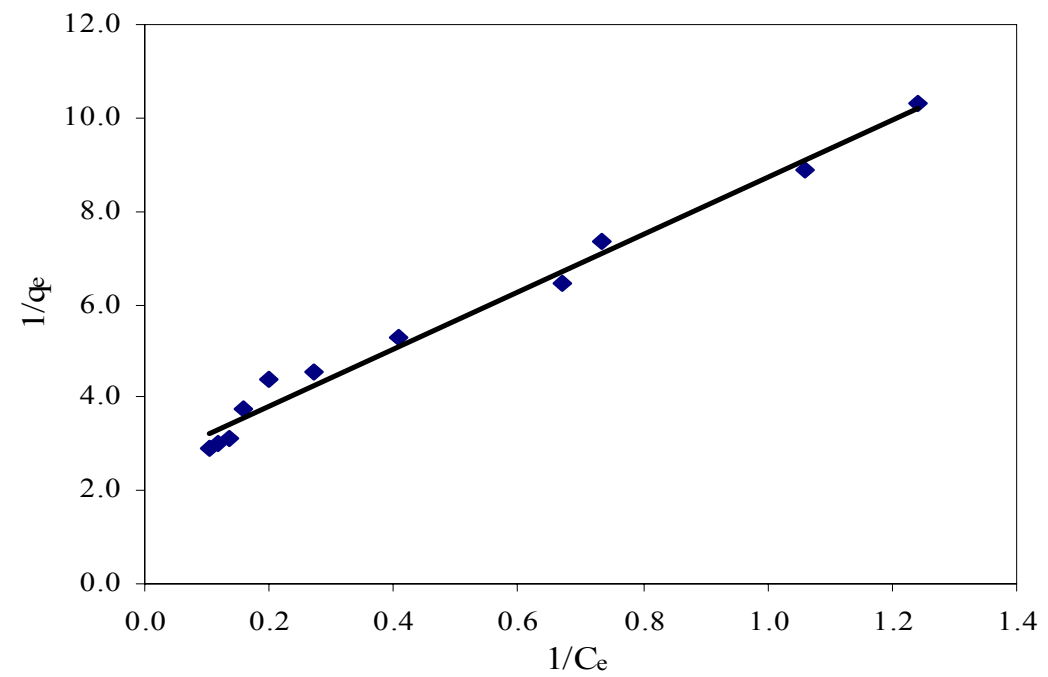

Fig. 6: $\quad$ Linear Langmuir isotherm of Fe (II) sorption on SDC 
The linear Freundlich equation can be expressed by [3]

$$
\log q_{e}=\frac{1\left(\log C_{e}\right)}{n}+\log K_{f}
$$

where the slope of the graph represented by $1 / n$ and $\log K_{f}$ is shows the interception of the graph on the Y-axis. The value of $K_{f}$ indicates the adsorption capacity and the constant $n$ refers to the empirical constant related to the strength bonding between $\mathrm{Fe}$ and the sawdust. The linear line of Freundlich equation fitted linearly into the experimental data as shown in Figs. 7 and 8.

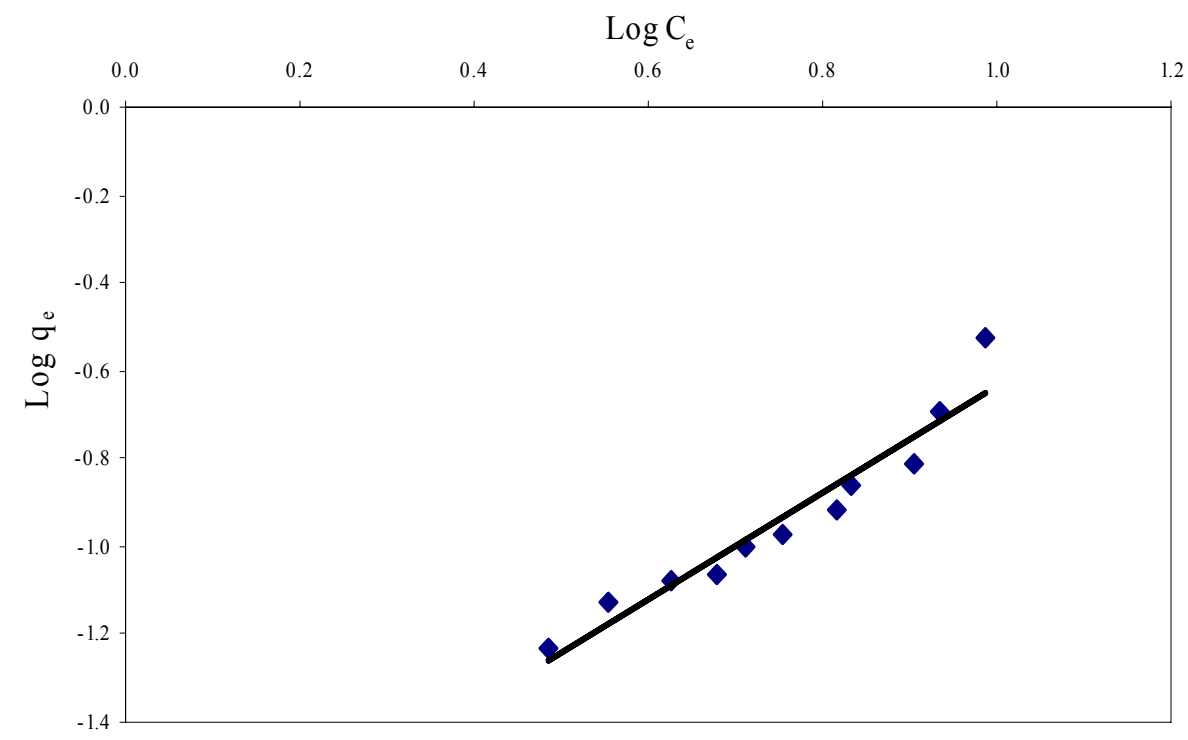

Fig. 7: $\quad$ Linear Freundlich isotherm of Fe (II) sorption on SD

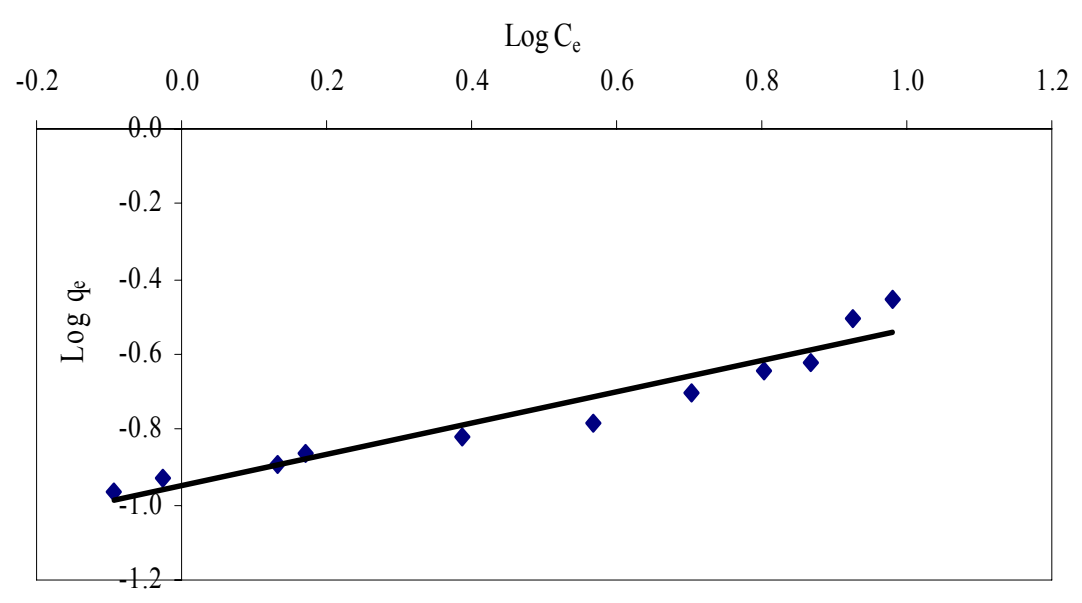

Fig. 8: $\quad$ Linear Freundlich isotherm of Fe (II) sorption on SDC

All the related parameters of the linear Langmuir and Freudlich equations for Fe on sawdust in aqueous solutions are summarized in Tables 1 and 2. A comparison is also being made between the three isotherms plotted in Figs. 9 and 10. As shown by Table 1, the Langmuir and the Freudlich isotherms were satisfactory fitted to the experiment data as indicated by their correlation coefficients. The Langmuir isotherm shows a better fit of adsorption data as compared to that of the Freudlich isotherm. It can be concluded that the chemical absorption or 
chemisorption and physical absorption or physisorption processes were the main mechanisms of adsorption that occurred between the sawdust and iron. It is due to the formation of a chemical bond between the absorbing molecules and the surface of the sawdust. The results also show that the chemisorptions process is more dominant as compared to physisorption.

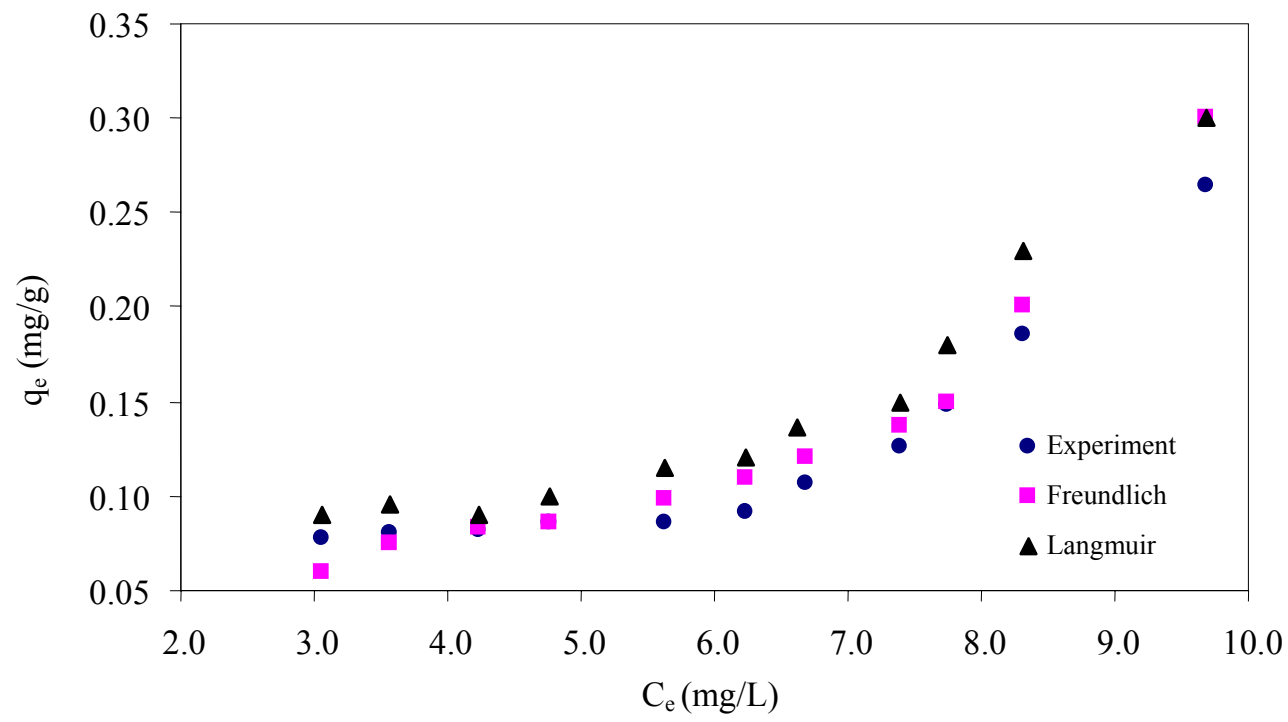

Fig. 9: $\quad$ Fitting of Langmuir and Freundlich isotherm into the experiment data for SD

Table 1: $\quad$ Langmuir adsorption equation for SD and SDC

\begin{tabular}{ccc}
\hline Langmuir isotherms & Untreated sawdust (SD) & Treated sawdust (SDC) \\
\hline Langmuir equation & $q_{e}=\frac{0.1726 C_{e}}{1+0.5398 C_{e}}$ & $q_{e}=\frac{0.1628 C_{e}}{1+0.4236 C_{e}}$ \\
Constant a (mg/g) & 0.3198 & 0.3844 \\
Constant b (L/mg) & 0.5398 & 0.4236 \\
$\mathrm{R}^{2}$ & 0.9844 & 0.9865 \\
\hline
\end{tabular}

Table 2: $\quad$ Freundlich adsorption equations for both SD and SDC

\begin{tabular}{ccc}
\hline Freundlich isotherms & Untreated sawdust (SD) & Treated sawdust (SDC) \\
\hline Freundlich equation & $q_{e}=0.0138 C_{e}^{1.2291}$ & $q_{e}=0.1122 C_{e}^{0.4196}$ \\
Adsorption capacity, $\mathrm{k}_{\mathrm{f}}$ & 0.0138 & 0.1122 \\
$\mathrm{n}$, constant & 0.8136 & 2.3832 \\
$\mathrm{R}^{2}$ & 0.9238 & 0.9249 \\
\hline
\end{tabular}




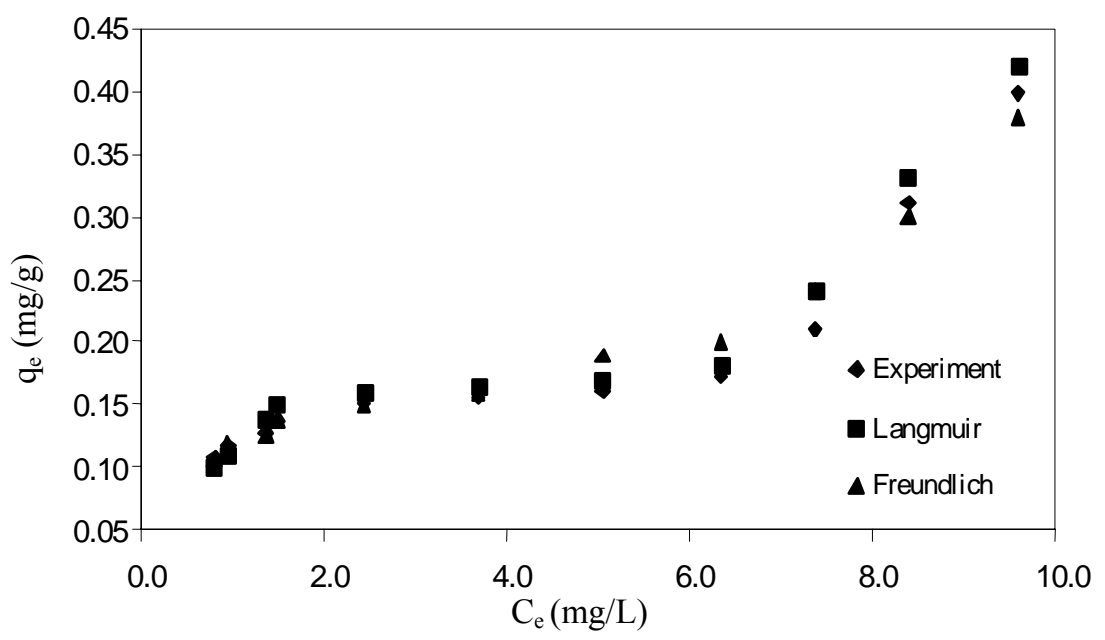

Fig. 10: Fitting of Langmuir and Freundlich isotherm into the experiment data for SDC

\section{CONCLUSIONS}

The results of the investigation have shown that sawdust was found to be a promising absorbent for the removal of iron from aqueous solutions. The treated sawdust has more capability in removing iron as compared to that of untreated or the natural sawdust. Adsorption of the iron is dependent on the initial concentrations of absorbent and the sorbate. The Langmuir isotherm was found well fitted into the experimental data as compared to that of the Freudlich isotherm in their adsorption processes. Based on this finding, the chemisorption and physisorption were the main mechanisms of adsorption that occurred between iron and the sawdust. Adsorption mechanisms studies revealed that the chemisorptions process gives a significant contribution as compared to that of physisorption.

\section{ACKNOWLEDGEMENT}

We gratefully thank Mr. Asmadi Ali of Department of Engineering Science, KUSTEM for his valuable suggestion about method for the removal of iron in aqueos solution. We would like to acknowledge the financial support from KUSTEM.

\section{REFERENCES}

1. Shukla, S.S., Yu, L.J., Dorris, K.L., and Shukla, A. (2005), Removal of nickel from aqueous solutions by sawdust, J. Haz. Mat., vol. 121, pp. 243-246.

2. Yu, B., Zhang, Y., Shukla, A., Shukla, S.S., and Dorris, K.L. (2001), The removal of lead from aqueous solutions by sawdust adsorption, J. Haz. Mat., vol. 84, pp. 83-94.

3. Özacar M. and Sengil, I.A. (2005), Adsorption of metal complex dyes from aqueous solution by pine sawdust, Bioresour Technol., vol. 96, no. 7, pp. 791-795.

4. Ajmal, M., Khan, A.H., Ahmad, S., and Ahmad, A. (1998), Role of sawdust in the removal of copper (II) from industrial wastes, Wat. Res., vol. 32, no. 10, pp. 3085-3091.

5. Shukla, A., Zhang, Y.H., Dubey, P., Margrave, J.L., and Shukla, S.S. (2003), The role of sawdust in the removal of unwanted materials from water, J. Haz. Mat., vol. 95, pp. 137-152. 